\title{
Plate Heat exchanger Model as Part of INDIRECT HEATING SUBSTATION
}

\author{
Armin Teskeredzic \& Rejhana Blazevic
}
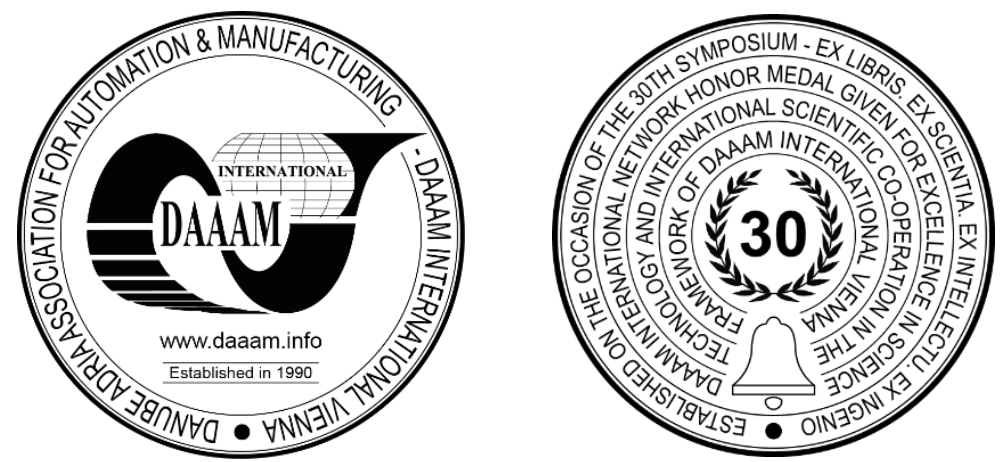

This Publication has to be referred as: Teskeredzic, A[rmin] \& Blazevic, R[ejhana] (2019). Plate Heat Exchanger Model as Part of Indirect Heating Substation, Proceedings of the 30th DAAAM International Symposium, pp.0709-0716, B. Katalinic (Ed.), Published by DAAAM International, ISBN 978-3-902734-22-8, ISSN 1726-9679, Vienna, Austria DOI: $10.2507 / 30$ th.daaam.proceedings.097

\begin{abstract}
Plate heat exchangers (PHEX) are core parts of the indirect heating substations in the district heating systems. As a result of different energy efficiency measures at the consumption side and decreased demand, the key parameters of the existing substation have to be changed. The exchanger will operate in conditions far from the design parameters and it is of crucial importance to predict the PHEX operation under the new regimes. Standard calculation tools available by PHEX producers offer the possibility to select the best fit PHEX and then to test its behaviour in the performance mode by changing parameters at both sides of the exchanger. However, the interaction of PHEX with other heating components is not possible within these tools. This paper focuses on the application of the in-house developed tool for single pass PHEX modelling which is calibrated based on the results of the available software tools by two producers. It is shown in both selected cases that the discrepancy between results of the in-house model and the producer's data are less than $2 \%$ for the key selected parameters. Calibrated model is than implemented into the Modelica Buildings library and the simple model of the substation connected to the consumer is designed. Thermal refurbishment of the consumer is simulated in the model and the PHEX started to operate under the regime far from design conditions. New settings for weather compensated control are implemented and obtained results for PHEX are again verified against the producer software. It is shown that the discrepancy between the model results and producer software remained at the same level of up to $2 \%$. Advantages of the proposed concept are highlighted and the recommendations for further work are given.
\end{abstract}

Keywords: plate heat exchanger model; indirect heating substation; district heating; Modelica Buildings library

\section{Introduction}

Energy efficiency measures and programs are strongly promoted by the current European Union strategic documents and Energy efficiency directive [1]. The fourth generation of the district heating systems [2] have been promoted which assumes, among other things, the decrease of the supply temperature, while the level of energy efficiency increases. This can only be done if the consumer temperature level is lower than what used to be a design standard for a long time. In South East Europe the temperature levels in the district heating systems are still high, since the heating systems in buildings are in most cases designed for the $80 / 60^{\circ} \mathrm{C}$ (supply/return) temperature regime and even $90 / 70^{\circ} \mathrm{C}$ in some cases.

When these customers are connected to the district heating network via indirect heating substations, the existing heat exchangers are sized for high level temperatures and heat loads. If the energy efficiency measures are applied at the 
consumer side, the heat demand can be decreased up to $50 \%$ and even more in some cases. Decreased demand tremendously changes the operation of the existing heat exchanger and its optimisation and fine tuning become a challenge. When only a part of the customers, connected to the district heating system, undergo energy efficiency refurbishment measures, the primary supply temperature will remain unchanged, while the temperature level at these consumers will be considerably lower. In order to decrease the heat flux from primary to secondary side of the exchanger in these cases, the flow at the primary side needs to be significantly smaller.

Differences in flows and temperatures will influence the overall heat transfer coefficient ( $U$-value) in the exchanger. If the heat balance calculation is performed with constant $U$-value (nominal $U$-value of exchanger) for the near design conditions, a reasonable accuracy can be expected. But if the working regime of the exchanger is significantly changed, as a result of decreased demand, the constant $U$-value approach can introduce large computational errors. This paper focuses on more precise $U$-value estimation for the model of heat exchanger, which allows the existing and now oversized heat exchangers to be optimised for the new needs.

Different kind of optimisations in the district heating systems have been performed by the use of advanced Modelica based calculation tools [3] in last couple of years. Calibration and validation of different Modelica system models simulating the photovoltaic modules, solar thermal collector, ventilation and heating systems are implemented in [4] where the district heating systems are analysed in order to reduce the power peaks re-delivered to the grid by a renewable district heating system. Thermal and hydraulic dynamic behaviour of district heating grids are simulated and the models of heating power plants are developed in [5]. Advanced control methods for variable temperature district heating systems by using dynamic simulations are presented in [6] where the thermal storage capacity of the network is dealt with and the compromise between the pumping costs and heat losses are discussed. Stratified thermal energy storage system coupled with the biomass gasifier is presented in [7] in order to increase the overall utilisation factor of the system.

Models of the heat exchangers are presented in [8] in which the validation is performed for one commercial heat exchanger connected to the district heating grid. In [9] a heat exchanger is simulated as a combination of $\varepsilon$-NTU model and an ideal regulator of the secondary outlet temperature, while in [10] the finite element method is applied for the discrete model of the heat exchanger. Simulation tools are also used to analyse different configuration schemes and design options during the preparation phase of the district heating project [11]. Complete District Heating Modelica library is presented in [12] with package substation and an application of the developed library.

In this paper an in-house developed model for PHEX is used and implemented in the Modelica building Library where it is further used for analysis of the energy efficiency measures implemented at consumer side.

\section{Indirect heating substations and heat exchanger modelling approach}

In the district heating applications, counterflow heat exchangers are used with almost no exception and only the counterflow HEX with the single pass will be treated in this paper. Weather compensated control [13] is used where the heat delivered to final consumers is dependent on the heat curve supply temperature, while preserving the constant mass flow in the secondary network. The desired secondary supply temperature, dependent on the outside temperature, is achieved by varying the flow through the primary side of heat exchanger.
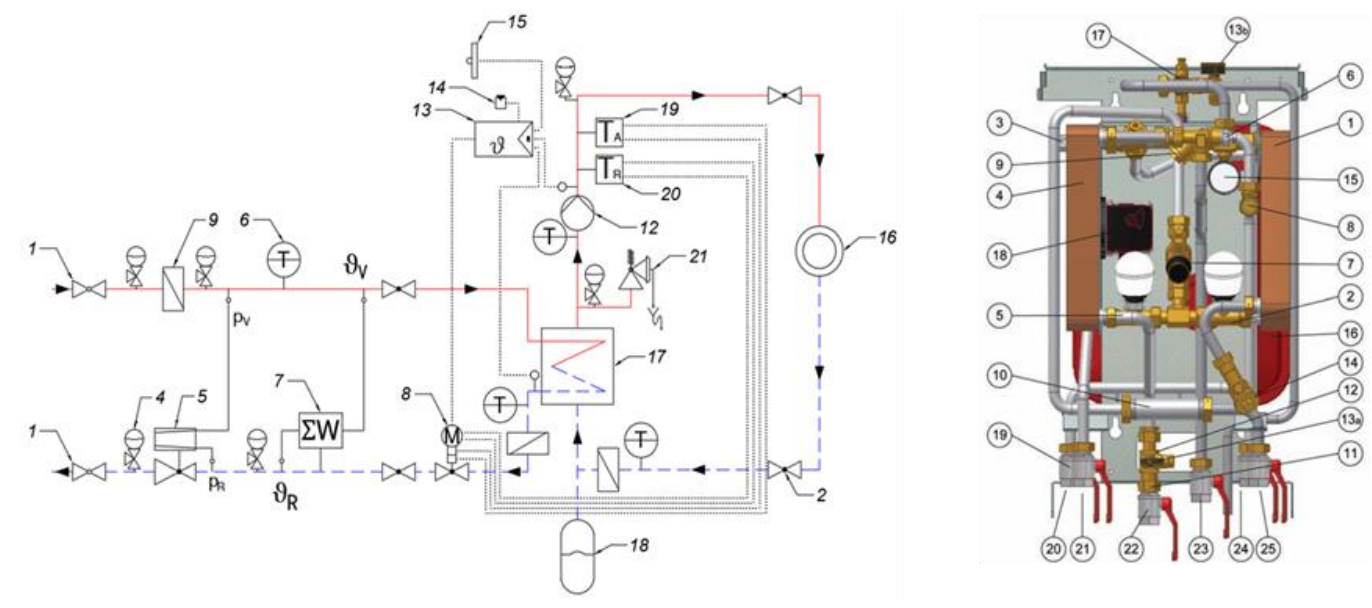

Fig. 1. Indirect heating substation (scheme - left, compact station - right) connected to district heating system

Scheme of the indirect heating substation is shown in Fig. 1. (left), where primary and secondary side are hydraulically separated by heat exchanger (17). At the primary side, the differential pressure controller (5) is installed which keeps approximately constant differential pressure across the control valve (8) and ensures that the valve authority is maintained at the desired level.

The temperature sensor, which is placed in the supply secondary network before the circulation pump (12), measures the water supply temperature and sends the signal to the controller (13). At the same time measured value of the outside 
temperature (15) is sent to controller and the desired water supply temperature is known - it is defined by the heat curve settings at the controller. Based on the difference between desired and measured value of the water supply temperature, the controller adjusts the opening of the motorised two way valve (8) by changing the flow at the primary side. At the right hand side of Figure 1 a drawing of a compact house substation is given which has all key elements of the scheme presented in Figure 1 (left) including an additional heat exchanger for domestic hot water preparation.

As already explained in Introduction, the variation of the primary side flow can be significant and it is to be expected that the overall $U$-value of the exchanger will vary accordingly. In-house developed procedure for $U$-value determination is mainly based on the approach proposed in [14] in which the overall heat transfer coefficient in the heat exchanger is dependent on the flows and the temperatures at the heat exchanger inlets. As a result of the calculation procedure, the variable $U$-value of heat exchanger is obtained, which is in general expressed as function of the reference $U$-value and corrected for mass flows and/or temperature regimes from both sides of the exchanger. When $U$-value formulation is obtained, the HEX model is tested against all possible regimes, including variable temperatures and mass flows at HEX inlet.

The in-house developed procedure contains 6 characteristic steps, such as:

1. Model of the HEX is adopted based on the recommendation of the producer software tool (for example http://www.ssponline.swep.net) in the design mode. Required known parameters are the heat load of the exchanger and supply and return temperatures from the both sides of exchanger. Note that the primary hot water supply temperature is given by the district heating company, while the consumer side parameters are known in advance.

2. Chosen model of exchanger is then calibrated in the performance mode of the producer software tool. Within this step different input parameters are prescribed from both sides of the exchanger. Variable inputs are inlet temperatures and mass flows from both sides of exchanger, while the outlet temperatures and heat loads are recorded. Procedure is repeated for 15 characteristic and different values at inlets of the exchanger.

3. Based on the results obtained in the step 2 for the selected HEX in step 1, an in-house developed tool is used to determine the reference U-value and the mass and temperature correction factors. Existing methodology is targeted to minimise the sum of the square errors between the thermal energy balance of the exchanger and the recorded data in step 2.

4. In step 4 the heat curve parameters at the consumer side and the primary temperature variation are set (known from the district heating company) and the calculations are performed for the whole range of outside temperatures started from the design value with increment of $1{ }^{\circ} \mathrm{C}$. As a result, the mass flow at the primary side of exchanger is known for every outside temperature value.

5. Results obtained by using the in-house tool within step 4 are taken and again verified against the producer software tool in the performance mode. Seven characteristic input values different than the ones used in step 2 are compared and the final verification of the model is discussed.

6. Obtained values of the reference U-value and mass and temperature corrections are implemented in the existing HEX model of Modelica Buildings library as part of the heating substation and the results are again verified on existing data.

\section{Results and discussion}

In this section the explained procedure is applied onto two models of heat exchangers. As a basis for calculation, two software tools from different heat exchanger producers are taken and used for the analysis. One is the Danfoss desktop tool Hexcalc (https://www.danfoss.com/en/service-and-support/downloads/dcs/hexact/\#tab-overview) and the second is web based tool SSP online calculation software by SWEP (http://www.ssponline.swep.net/default.htm). In both cases the same heat load and temperature regimes of the heat exchanger are taken as a baseline. After the described procedure is completed, in both cases the reference $U$-values, mass and temperature corrections are obtained. It has to be said that the reference $U$-values does not necessarily means the nominal $U$-values of the heat exchanger. This is rather reference point for which the current expression on variation of $U$ shows the least discrepancy between the calculated values and producer results.

After the $U$-value expression is determined, it is implemented into the Modelica Buildings Library within the package which defines the $U A$ value. Modelling approach in Modelica was to prescribe the constant pressures of the source and sink assuming that the differential pressure controller is installed at the heating substation. The consumption side is modelled by the existence of the simplified building/room model which may take into account the thermal inertia of the multi-layer wall structure with different thermo-physical properties, windows and the infiltration of the outside air, previously prescribed by the user. Radiators are the heating elements in the room/building and no thermostatic valves are installed. 

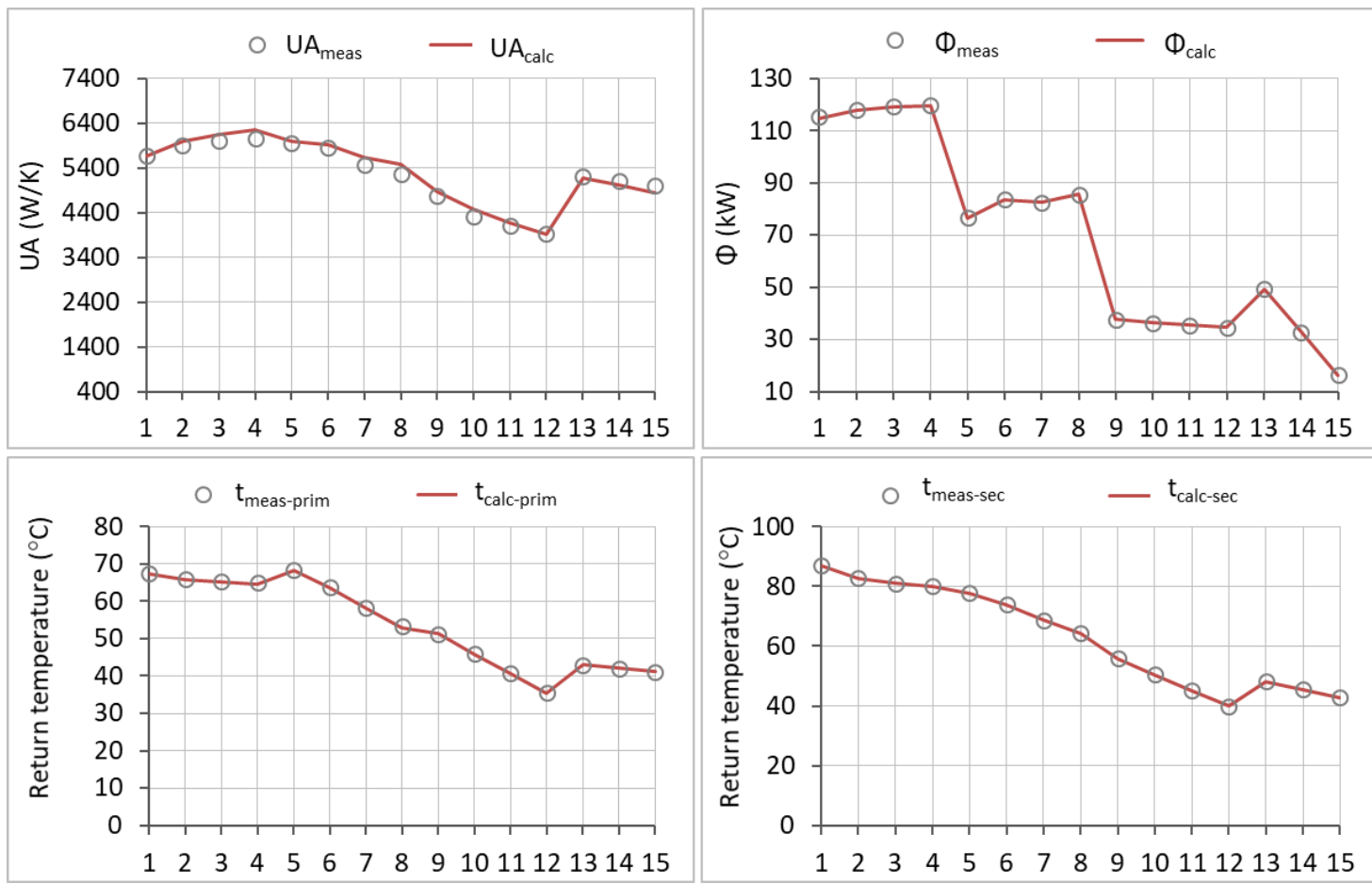

Fig. 2. Comparison of calibrated values for in-house tools versus values by producer software tool.

In Figure 2 the results of the implemented procedure are shown in four characteristic graphs. For the data set of 15 elements (step 2 of in-house procedure) with different values as input parameters, heat exchanger was tested against different conditions from both sides; primary and secondary. Even if the flow at secondary side is assumed constant, because of the weather compensated control strategy, the flow variation is applied to the secondary side as well. Top left graph in Figure 2 is the $U A$ value of the HEX, where index mes denote values from the producer software, while the calc index represents the calculated quantities. As one may notice the $U A$ value varies significantly for the test data sets and calculated values are very close to the producer values (Note that $A$ is the area of the exchanger and remains constant once the HEX is selected). Graph at the top right represents measured and calculated heat load of the HEX. It can be noticed that the HEX is tested against the $10 \%$ to $100 \%$ heat load, which gives enough information for the reliable determination of the $U$-value. Two graphs at the bottom of Figure 2 are comparison of outlet temperatures at primary and secondary side of the HEX. It can be said that for entire test range and for different variables the agreement is excellent.
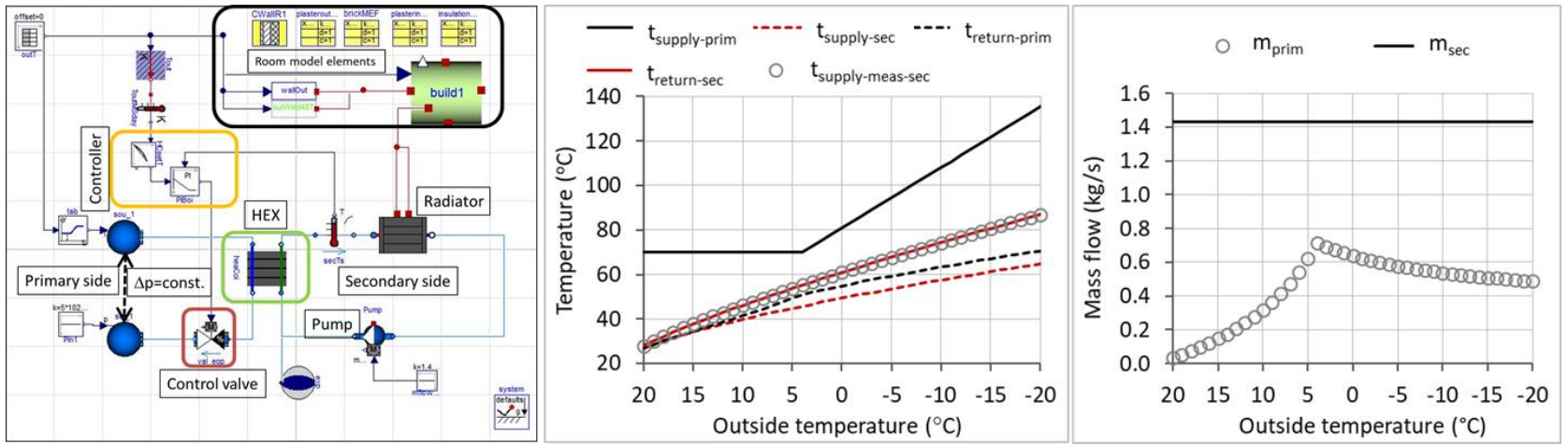

Fig. 3. Heating substation model (left) and results of the calculation (right) performed within step 6 of described procedure.

In Figure 3 (left) the model of the heating substation in Modelica within Dymola environment is presented. Simplified room/building model is shown at the top right hand side of the model, including the records in yellow boxes with definition of the thermo-physical properties for different layers at the outside walls. Simplified windows model is also incorporated by the transmission element without thermal mass [15] and [16], which allows user prescribed definition of $U$-value for windows. Infiltration is modelled via predefined room air changes per hour, which in this case remains the same during the calculations. One of the room heat ports is connected to the radiator which is part of the secondary or consumer network. 
Since the hydraulics analysis was not the target of the present work, resistances of the pipes are assigned to the heat exchanger pressure drop by assuming the complete hydraulic roughness of the pipes. Circulation pump, placed in the consumer side, is set up to provide constant mass flow in the secondary network. For the testing purposes and in order to avoid the influence of the outside walls thermal inertia, specific heats and densities for all wall layers are set to near zero values (1.e-03). It means that for every outside temperature the heat load at the exchanger will be exactly the same as the heat loss of the building in the steady-state condition for prescribed temperature. Equal percentage two-way motorised valve is placed in the primary return pipe which controls the supply temperature at the secondary side by changing the flow at the primary HEX side.

Differential pressure controller is not modelled as part of this substation, since the constant differential pressure is maintained by setting the constant pressure values at both - source and sink. For the HEX verification purposes, the ideal sizing of the heating system is assumed. It means that the heat losses of the building are exactly the same as the radiator power, which at the end is equal to the nominal heat load of the selected HEX. Note that the verification of existing model included the model of the consumption side and not only the HEX itself.

At the right hand side of Figure 3 the supply and return temperature values of primary and secondary flows are given for all range of outside temperatures as well as the mass flows at the primary side (circles) and secondary side (green line).
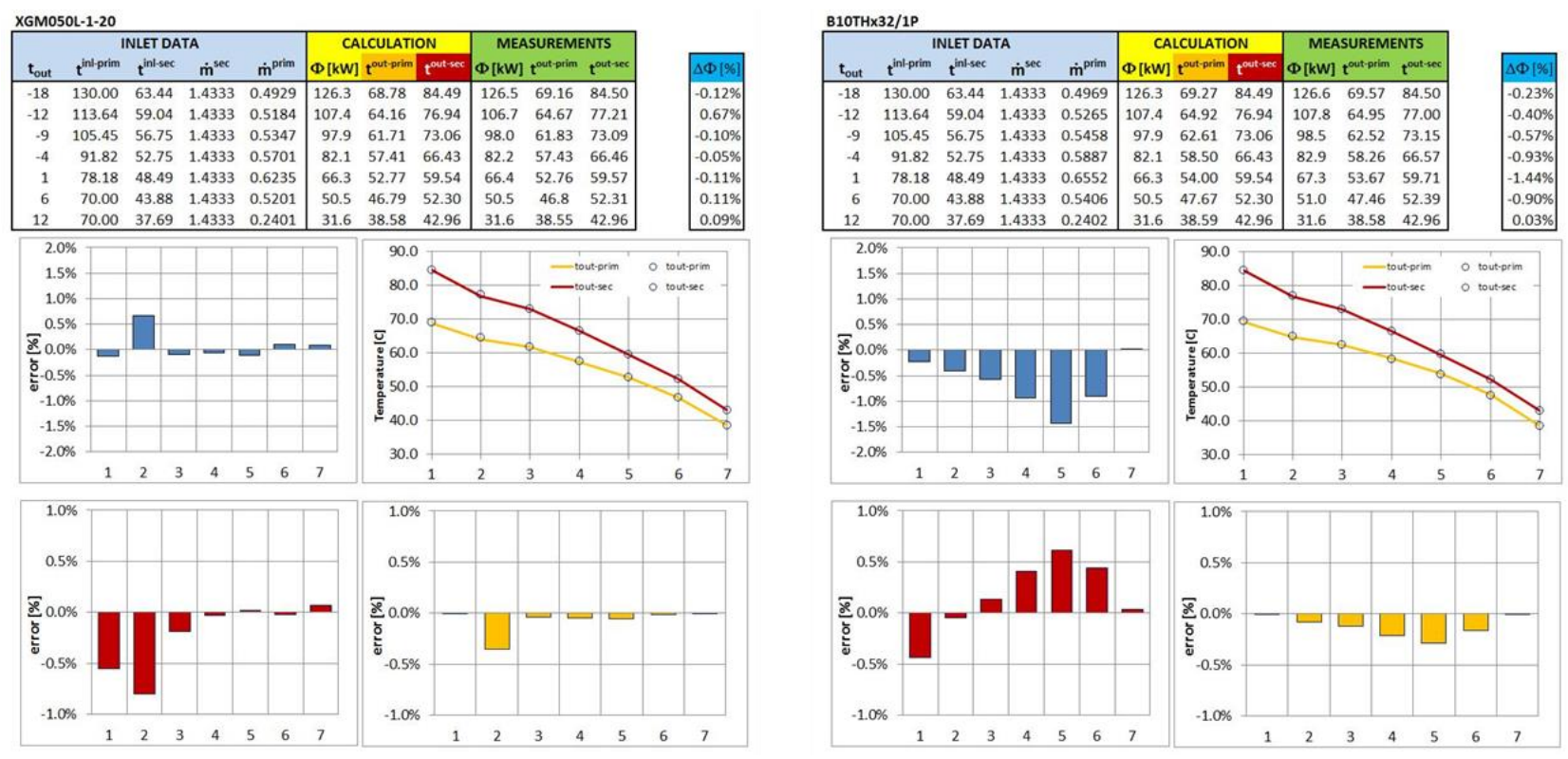

Fig. 4. Calculations (own) with producers (Hexcalc by Danfoss left and SSP7 by SWEP right).

For the performed calculations the primary supply temperature is set to be dependent on the outside temperature and varies linearly from $70^{\circ} \mathrm{C}$ for $t_{\text {out }}=4^{\circ} \mathrm{C}$ to $130^{\circ} \mathrm{C}$ for $t_{\text {out }}=-18^{\circ} \mathrm{C}$, while it remains constant for $\mathrm{t}_{\text {out }} \geq 4^{\circ} \mathrm{C}$ (see Figure 3 right). Radiator regime in nominal conditions is defined with $120 \mathrm{~kW}$ for $80 / 60 / 20$. Note that it is assumed that room temperature is set to $22^{\circ} \mathrm{C}$ at the controller and therefore the heat load of the exchanger is increased for nominal outside temperature of $-18^{\circ} \mathrm{C}$.

In Figure 4 the comparison between the calculated values and results of the two producer software tools is presented. On the left hand side of the Figure 4 the comparison for Danfoss XGMOSOL-1-20 is shown, while at the right hand side the comparison for SWEP B10TH $\times 32 / 1 \mathrm{P}$ is given. Three characteristic parameters are compared such as the heat load and the primary and secondary outlet temperatures. For the Danfoss exchanger the maximal relative error in terms of the heat load is less than $0,7 \%$ percent, while the outlet temperatures remain below $1 \%$ relative error. At the same time for the SWEP model, the relative error in terms of the heat load is less than 1,5\%, while the temperatures at the HEX outlet are around plus/minus $0,6 \%$.

Verification procedure is performed successfully with acceptable discrepancy between the calculations obtained by the Modelica model and the producer software tools in both cases. For the further analysis the SWEP model $\mathrm{B} 10 \mathrm{TH} \times 32 / 1 \mathrm{P}$ is used for two additional calculations. In both cases a period of 6 days (144 hours) is analysed with the assumption that the heating system was permanently ON without intermittency.

First calculation is based on the fact that the energy efficiency measures are implemented at the consumer side. In this particular case it is supposed that the thermal insulation of $10 \mathrm{~cm}$ is added to the outside walls and that the existing windows are replaced with new windows. Calculations are performed by keeping the same settings at the controller of the two-way motorised valve. It is expected that due to the open loop control and as a result of significantly decreased heat demand - the obtained room temperature will increase accordingly. As the room temperature goes up, the return 
temperature at the secondary side will increase and also the return temperature at the primary side will go up as well. It can be noted that the prescribed room temperature at the controller is set on $22^{\circ} \mathrm{C}$.
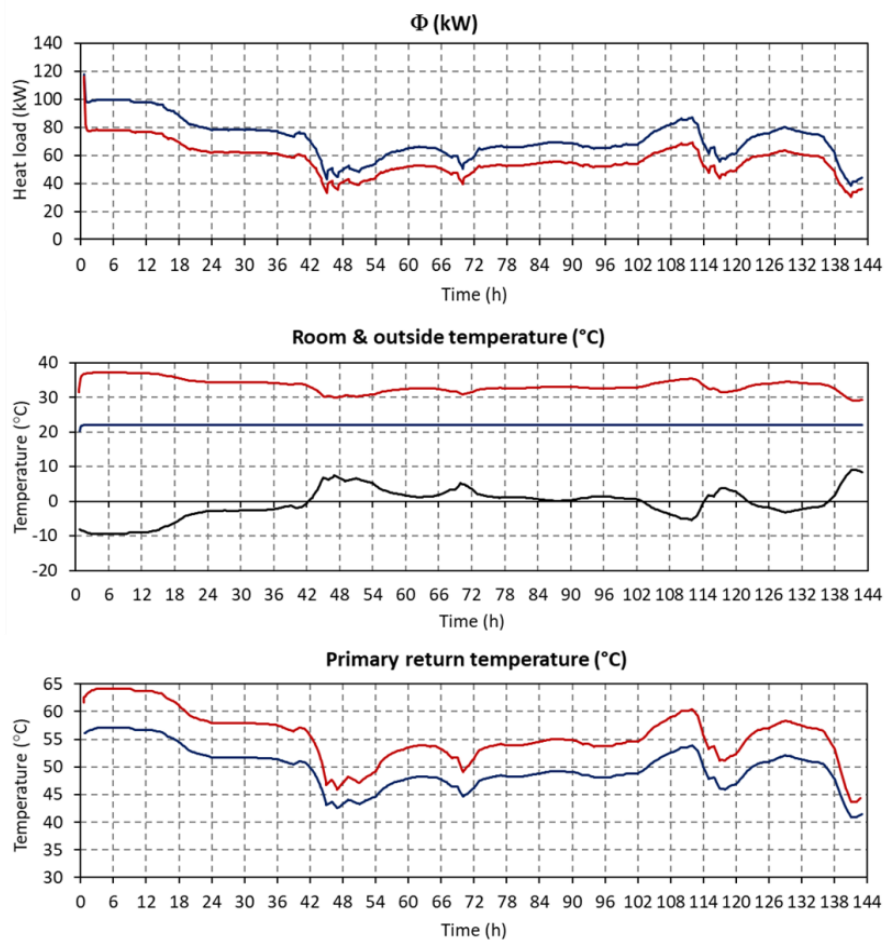

Fig. 5. Heat load (top), room and outside temperatures (middle) and primary return temperatures (bottom) for the reference case (blue lines) and case with building refurbishment (red lines).

Figure 5 shows the results of calculations for ideally sized heating system with nominal heat load of $120 \mathrm{~kW}$ (blue lines) and the refurbished building but with the same controller settings as in a reference case. This is a demonstration case in which the room temperature goes over $36^{\circ} \mathrm{C}$ for the case of refurbished building with the same settings at the controller. Heat load of the exchanger is smaller but not in the proportion with decreased heat demand by building (Figure 5 top). Also at the Figure 5 (bottom) it is visible that the primary return temperature increased for the case of refurbished building which is not acceptable by the district heating company.
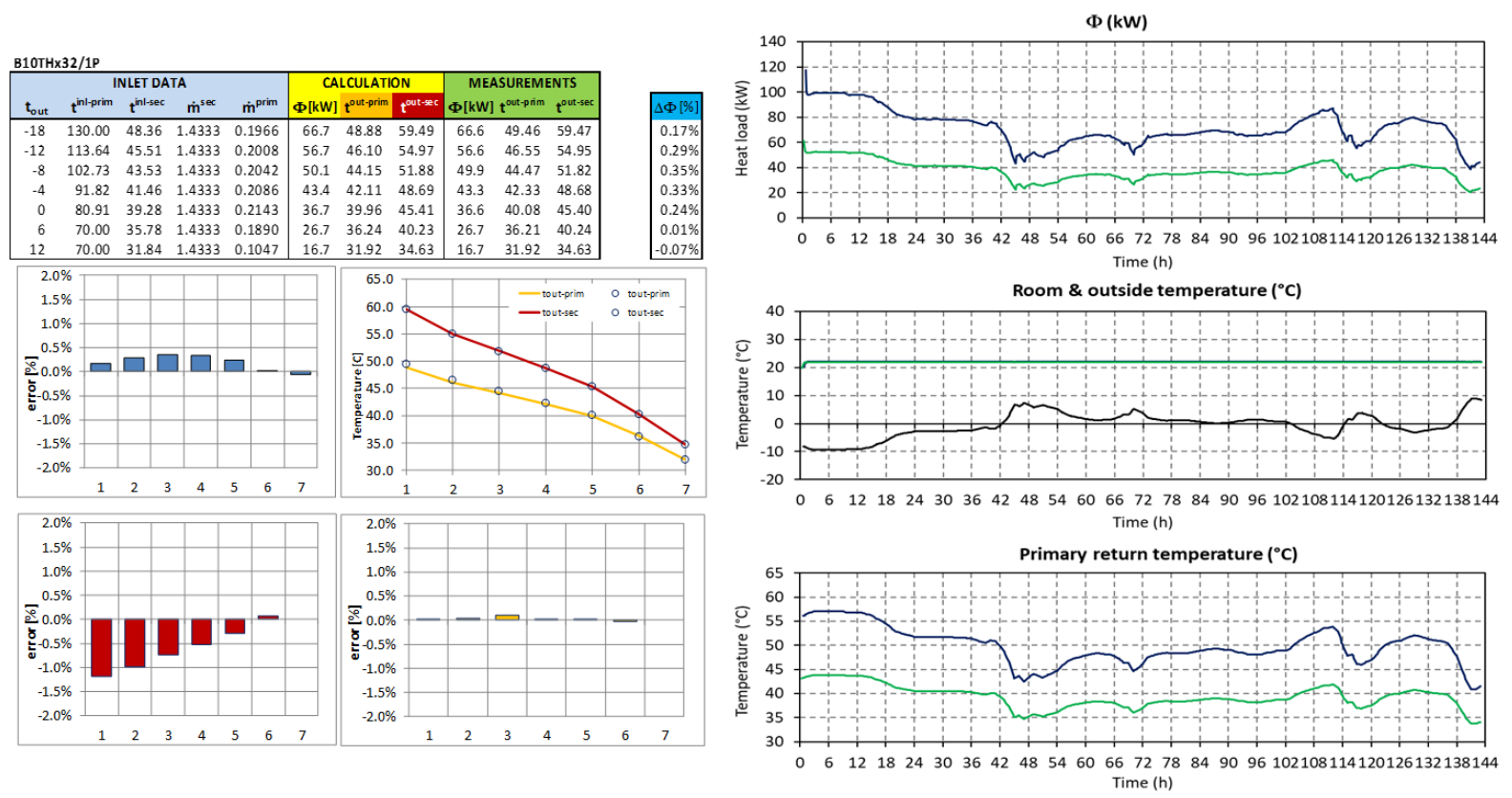

Fig. 6. Comparison of SWEP web based tool results with in-house model (left) and the comparison of characteristic values for conditions before and after the refurbishment of building (right). 
The final additional calculation is performed for the refurbished building and after the fine-tuning of the controller settings for the decreased heat demand. It is adopted that the secondary side will work in the regime 56/45/20, while preserving the same mass flow - without the intervention at the system hydraulics.

Figure 6 (left) again shows an excellent agreement between calibrated HEX model and the results of the SSP Online tool by SWEP. Although the exchanger was selected and calibrated for the design heat load of $120 \mathrm{~kW}$, the results showed that $U$-value of exchanger was properly defined within step 2 of the in-house developed procedure. Please note that the HEX is now working in the completely different temperature and flow regimes and the results of the calculations produce the relative error slightly above the $1 \%$ compared to the producer software web tool, calculated in the performance mode. This final verification also proves that the in-house developed model can be used for similar problems in the district heating systems.

Figure 6 (right) shows the results of calculation for the reference case of $120 \mathrm{~kW}$ heat load (blue lines) and the new conditions after the building refurbishment and different control settings (green lines). In this case it can be noted that the heat load of the exchanger decreased and it is fully compatible with the head demand decrease by the building (Figure 6 - top, right). Also, as a result of proper controller settings, the room temperature remains constant during the whole calculation period of 144 hours (Figure 6 - middle, right). At the Figure 6 bottom - right, the primary return temperature is shown for the reference and refurbished case with adjusted control settings. It is visible that the return temperature decreased significantly for the case of refurbished building, which should always be targeted in these case and which is preferred by the district heating company.

\section{Conclusion and further work}

This paper focuses on two important problems relevant for modern district heating systems. One is the adequate model of the plate heat exchanger able to produce reliable results under the different working conditions, which may be far from the design values. In-house developed procedure is verified against the results of two software tools, offered by different producers of heat exchangers. Results of calculations remained under the $2 \%$ relative error compared to the producer data, even for the case where the HEX was operating under the significantly decreased heat load.

Another important issue is the fact that the calibrated HEX is implemented into the Modelica Buildings library which allows analysis for different heating components interaction. In this paper a demonstration case is shown where the energy efficiency measures are implemented at the consumption side and two cases were analysed. One case demonstrated what happens if the weather compensated control settings remain the same for refurbished building. Results showed significant overheating of consumer, increased primary return temperature and less use of the energy savings potential. Second case simulated refurbished building with the proper weather compensated control adjustments, which resulted in required consumer temperature, use of the full potential of energy savings and the decreased primary return temperature. The latest can be very important for district heating companies.

Introduced calculation approach allows many other problems to be dealt with, such as: oversized or undersized radiators, oversized pump and increased flow at the consumer side, correct settings of the differential pressure controller in the heating substation, influence of the thermal inertia of outside and inner walls in buildings on control settings and many other things. Future work assumes application of the in-house developed procedure at the HEX under operation, where the calibration will be performed based on the measured values at HEX inlets.

\section{References}

[1] Directive 2012/27/EU of energy efficiency (EED) of the European Parliament and of the Council of 25 October 2012. Off. J. Eur. Union, (2012). 315, pp. 1-56.

[2] Lund, H., Werner, S., Wiltshire, R., Svendsen, S., Thorsen, J.E., Hvelplund, F. \& Mathiesen, B.V. (2014). 4th Generation District Heating (4GDH) Integrating smart thermal grids into future sustainable energy systems, Energy, Vol. 68, 2014, pp. 1-11., ISSN: 0360-5442, DOI: 10.1016/j.energy.2014.02.089

[3] https://simulationresearch.lbl.gov/modelica/, (2019). Modelica Buildings Library, Accessed on: 2019-07-22

[4] Torrens Galdiz, J.I., Xu, L. \& Hensen, J.L.M. (2016). Modelica for design of building and district energy systems: IEA EBC Annex60: Research projects demonstrating the benefits/utilization of Modelica, Bouwfysica, Vol. 2016, No. 2, 2016, pp. 28-35., ISSN: 0928-5377

[5] Schwan, T., Ziessler, O., Eckhardt, T. \& Unger, R. (2019). A Modelica-Based Framework for District Heating Grid Simulation, Proceedings of the 13th International Modelica Conference, 4 - 6 March 2019, Regensburg, Germany, ISSN 1650-3740, ISBN 978-91-7685-122-7, Haumer, A. (Ed.), pp. 159- 168, Linköping University Electronic Press, Linköpings universitet, DOI: 10.3384/eco19157

[6] Giraud, L., Merabet, M., Bavière, R. \& Vallée, M. (2017). Optimal Control of District Heating Systems using Dynamic Simulation and Mixed Integer Linear Programming, Proceedings of the 12th International Modelica Conference, 15 - 17 May 2017, Prague, Czech Republic, ISSN 1650-3740, ISBN 978-91-7685-575-1, Haumer, A. (Ed.), pp. 141- 150, Linköping University Electronic Press, Linköpings universitet, DOI: 10.3384/ecp17132141

[7] Soons, F.F.M., Torrens Galdiz, J.I., Hensen, J.L.M. \& de Schrevel, R.A.M. (2014). A Modelica based computational model for evaluating a renewable district heating system, Proceedings of the 9th International Conference on System 
Simulation in Buildings, 10 - 12 December 2014, Liege, Belgium, ISBN 978-2-930772-10-3, pp. 1-16, Building Performance.

[8] Mattsson, S.E. (1997). On Modeling of Heat Exchangers in Modelica, Proceedings of the 9th European Simulation Symposium, ESS` 97, 19 - 23 October 1997, Passau, Germany.

[9] Giraud, L., Merabet, M., Bavière, R. \& Paulus, C. (2014). Modeling of solar district heating: a comparison between TRNSYS and MODELICA, Proceedings of the ISES EuroSun 2014 Conference, 16 - 19 September 2014, Aix-lesBains, France, ISBN 978-3-9814659-3-8, Frank, E. \& Papillon, P. (Ed.), pp. 696- 707, Published by International Solar Energy Society (ISES), DOI: 10.18086/eurosun.2014.19.06

[10] Grigore, R., Hazi, A. \& Hazi, G. (2010). Contributions regarding numerical simulation of fluid flow in a plate heat exchanger, Proceedings of the 21th International DAAAM Symposium "Intelligent Manufacturing \& Automation", 20-23 October 2010 Zadar, Croatia, ISSN 1726-9679, ISBN 978-3-901509-73-5, B. Katalinic (Ed.), pp. 579 - 580, Published by DAAAM International, Vienna, Austria, EU.

[11] Sartor, K. (2017). Simulation Models to Size and Retrofit District Heating Systems, Energies, Vol. 10, No. 12, 2017, pp. 1-14., ISSN: 1996-1073, DOI: 10.3390/en10122027

[12] Giraud, L., Bavière, R., Vallée, M. \& Paulus, C. (2015). Presentation, Validation and Application of the DistrictHeating Modelica Library, Proceedings of the 11th International Modelica Conference, 21 - 23 September 2015, Versailles, France, ISSN 1650-3686, E-ISSN 1650-3740, ISBN: 9789176859551 (print), Fritzson, P. \& Elmqvist, H. (Ed.), pp. 79-88, Linköping University Electronic Press, Linköpings universitet, DOI: $10.3384 /$ ecp 1511879

[13] Viessman, Climate of innovation (2012). Control technology - Weather compensated controls

[14] Wetter, M. (1999). Simulation Model Finned Water-to-Air Coil Without Condensation, Ernest Orlando Lawrence Berkeley National Laboratory, LBNL-42355

[15] Teskeredzic, A. \& Blazevic, R. (2018). Transient Radiator Room Heating-Mathematical Model and Solution Algorithm, Buildings, Vol. 8, No. 11, 2018, pp. 1-18., ISSN: 2075-5309, DOI: 10.3390/buildings8110163

[16] Blazevic, R. (2018). Advanced Modelling and Dynamic Simulation of the Heating System with the Simultaneous Application of Modelica and the Final Volume Method, Ph.D. Dissertation, Energy department, University of Sarajevo, Sarajevo, Bosnia and Herzegovina 